\title{
Urokinase in the management of traumatic hyphaema
}

\author{
W. RAKUSIN \\ Johannesburg
}

Department of Ophthalmology, University of the Witwatersrand, and Baragwanath Hospital,

There is no general agreement in the literature on the correct management of traumaticw hyphaema*-even about such minor points as whether to pad the injured eye only ord to pad both eyes, and whether to use a miotic or mydriatic or not. It was therefore decided in I 966 to treat a controlled series of cases of traumatic hyphaema with various preselected regimes. This prospective study was undertaken at Baragwanath Hospital and $\vec{N}$ extended over 3 years (1966-1969), when 370 consecutive cases were examined and treated. N A detailed report of this study is to be published elsewhere. One of the major findingso was that the prognosis was directly related to the size of the hyphaema (Table I). Theproblem of management thus mainly concerns the three-quarters to full hyphaemas, $\mathbb{\Phi}_{\mathbb{D}}$ since, in our experience, those occupying half the volume of the anterior chamber or lessळ have agood prognosis irrespective of the type of treatment and even with no treatment at all.

Table I Traumatic hyphaema treated according to size

\begin{tabular}{|c|c|c|c|c|}
\hline \multirow[t]{2}{*}{ Size } & \multicolumn{2}{|c|}{$\begin{array}{l}\text { Less than half } \\
\text { of volume of } \\
\text { anterior chamber }\end{array}$} & \multicolumn{2}{|c|}{$\begin{array}{l}\text { More than half } \\
\text { of volume of } \\
\text { anterior chamber }\end{array}$} \\
\hline & No. & Per cent. & No. & Per cent. \\
\hline No. of cases & 213 & & 157 & \\
\hline Raised intraocular pressure & 8 & $3 \cdot 8$ & 133 & $84 \cdot 7$ \\
\hline Incidence of complications & 47 & $22 \cdot 0$ & 123 & $78 \cdot 3$ \\
\hline Final vision of $6 / 18$ or better & I 66 & $78 \cdot 0$ & 44 & $28 \cdot 0$ \\
\hline
\end{tabular}

This paper reports our experience with the use of Urokinase as a fibrinolytic agent in: twenty cases of full hyphaema, associated with large blood clots in the anterior chamber, which could not be washed out with saline.

There have been many reports of the use of fibrinolytic substances $\dagger$, but these dealt with only eight cases or less, with no attempt to compare the results with those of other forms of treatment. None of the patients had previously been treated by anterior chamber wash- $\frac{D}{0}$ out with saline.

\section{Materials and methods}

In the early part of the study before Urokinase was available, the effect of conservative as against surgical management was investigated, 98 cases selected at random were treated conservatively $\ddagger$ and $\overline{<}$ 59 cases by immediate anterior chamber wash-out with saline through a small corneal incision.

Received for publication April 2, $197 \mathbf{r}$

Address for reprints: Department of Ophthalmology, University of Witwatersrand Medical School, Hospital Street, Johannesburg South Africa

*Rychener (1944), Laughlin (1948), Thyeson and Beard (1952), Duke-Elder (1954), Sorsby (1964), MacDonald (1964), Oksala (rg67) Darr and Passmore (1967)

†Pierse and Le Grice (1963, 1964), Scheie, Ashley, and Burns (1963), Heath (1966)

¥Cons ervative treatment comprised rest in bed, pad to the injured eye, topical antibiotic, cycloplegic, and miotic, and Diamox 
SURGICAL TEGHNIQUE

\section{Incision}

This was made with a von Graefe knife through the peripheral part of the cornea, $1-2 \mathrm{~mm}$. in front of the limbus. The incision was slanted within the corneal stroma so that suturing was unnecessary, and was extended to about $15^{\circ}$. The posterior lip of the incision was depressed with an iris repositor to evacuate the fluid blood from the anterior chamber.

\section{Irrigation}

Saline from a $2 \mathrm{ml}$. syringe with a blunt cannula was then introduced into the anterior chamber through the incision; care was taken to keep the tip of the cannula just within the incision and directed away from both the corneal endothelium and the lens capsule, i.e. over the iris and parallel to it. The anterior chamber was then gently irrigated with saline until it was free of blood.

\section{UROKINASE}

This was used in twenty cases in which anterior chamber wash-out with saline had failed to evacuate large blood clots. In eight cases, the patients were returned to the ward after anterior chamber irrigation with saline and were assessed the following day. They were then subjected to a second anterior chamber wash-out with Urokinase through the same incision. In the other twelve cases, Urokinase was used at the first operation after irrigation with saline had failed to remove blood clot.

The Urokinase was supplied fresh in ampoules by Leo Laboratories as a lyophilized powder and used soon after delivery. If some delay before use is anticipated, the Urokinase should be stored in a refrigerator. 5,000 units Urokinase solution was made up by mixing the powder with 2-ml. sterile distilled water. The anterior chamber was irrigated slowly, with $0 \cdot 3 \mathrm{ml}$. Urokinase solution and this was left in situ for 3 minutes and then washed out with saline. This procedure was repeated five times. With each introduction of Urokinase the clot became more friable and easier to disperse. If any residual clot was present at the end, $0.3 \mathrm{ml}$. Urokinase was left in the anterior chamber for 24-48 hours. This caused no harmful effects, and every small clot which remained in the anterior chamber after operation had dissolved completely within 48 hours.

\section{Results}

These were assessed by the following criteria in the twenty cases in which saline irrigation was unsuccessful:

(I) Rate of dispersal of blood from the anterior chamber;

(2) Incidence of complications of the hyphaema;

(3) Final visual acuity.

\section{(I) Rate of dispersal of blood}

In the eight patients in whom Urokinase was used on the next day, it was found that the blood clot had remained the same size and that the intraocular pressure was elevated.

With the use of Urokinase, the blood clot absorbed completely on the operating table in four cases.

In a further four cases it had dissolved before the first post-operative dressing on the first day, and in five more cases within 3 days.

Only two cases took longer than I week to absorb completely (one in 7 days and one on the 9th postoperative day), and it was felt that in these cases a higher concentration of Urokinase was necessary to dissolve the blood clot. This was achieved by using 10,000 units ( 2 ampoules) dissolved in $2 \mathrm{ml}$. sterile distilled water. In one case, in which 5,000 units Urokinase had had no effect, immediate irrigation with 10,000 units succeeded in dissolving the clot completely. 
A comparison between the group of full hyphaemas treated conservatively, those irrigated with saline alone, and those irrigated with saline plus Urokinase shows that the rate of absorption of blood from the anterior chamber (Figure) was slowest in the first group, more rapid in the second, and markedly accelerated in the last.

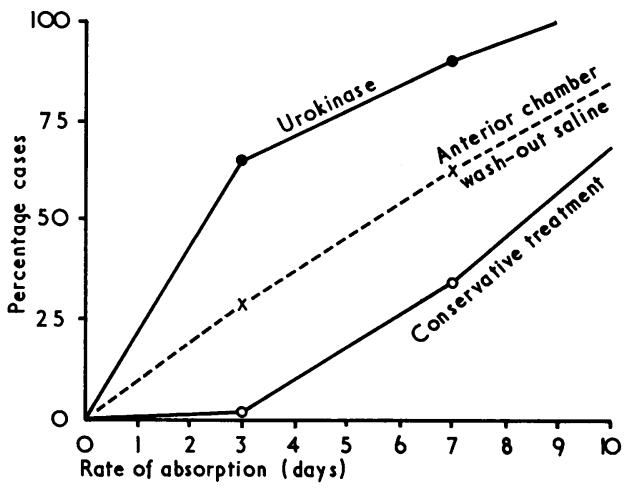

FIGURE Rate of absorption of blood from anterior chamber

With conservative treatment only 35 per cent. of hyphaemas had absorbed within IO week, whereas with saline irrigation 62 per cent. and with Urokinase irrigation 90 per cent. had absorbed completely within I week.

\section{(2) Incidence of complications}

The incidence of major complications before treatment (Table II) was least in the group treated conservatively, greater in the group treated with saline washout, and highest the group treated with Urokinase.

Table II Incidence of major complications before and after treatment

\begin{tabular}{|c|c|c|c|c|c|c|c|}
\hline \multirow{3}{*}{ Treatment } & & \multirow{2}{*}{\multicolumn{2}{|c|}{ Conservative }} & \multicolumn{4}{|c|}{ Anterior chamber irrigation } \\
\hline & & & & \multicolumn{2}{|c|}{ With saline } & \multicolumn{2}{|c|}{$\begin{array}{l}\text { With saline plus } \\
\text { Urokinase }\end{array}$} \\
\hline & & No. & Per cent. & No. & Per cent. & No. & Per cent. \\
\hline Corneal blood staining & $\begin{array}{l}\text { Before treatment } \\
\text { After treatment }\end{array}$ & $\begin{array}{l}27 \\
21\end{array}$ & $\begin{array}{l}27 \cdot 6 \\
21 \cdot 6\end{array}$ & $\begin{array}{l}29 \\
10\end{array}$ & $\begin{array}{l}49 \cdot 2 \\
16 \cdot 9\end{array}$ & $\begin{array}{l}2 \\
2\end{array}$ & $\begin{array}{l}60 \\
10\end{array}$ \\
\hline $\begin{array}{l}\text { Raised intraocular } \\
\text { pressure }\end{array}$ & $\begin{array}{l}\text { Before treatment } \\
\text { After treatment }\end{array}$ & $\begin{array}{l}85 \\
49\end{array}$ & $\begin{array}{l}85 \cdot 8 \\
49 \cdot 7\end{array}$ & $\begin{array}{l}56 \\
12\end{array}$ & $\begin{array}{l}94 \cdot 9 \\
20 \cdot 3\end{array}$ & $\begin{array}{r}20 \\
1\end{array}$ & $\begin{array}{r}100 \\
5\end{array}$ \\
\hline $\begin{array}{l}\text { Clotting in anterior } \\
\text { chamber }\end{array}$ & Before treatment & 19 & $19 \cdot 6$ & 29 & $49 \cdot 2$ & 20 & 100 \\
\hline $\begin{array}{l}\text { Fibrous membrane } \\
\text { formation }\end{array}$ & After treatment & 33 & $33 \cdot 7$ & 21 & $37 \cdot 9$ & 2 & 10 \\
\hline Total cases & & 98 & & 59 & & 20 & \\
\hline \multicolumn{8}{|c|}{$\begin{array}{l}\text { The effect of the type of treatment in reducing the incidence of complications is seen } \\
\text { most markedly in the group treated with Urokinase (where blood staining of the cornea } \\
\text { was reduced from } 6 \text { o per cent. before treatment to Io per cent. after treatment, raised } \\
\text { intraocular pressure from Ioo to } 5 \text { per cent., and fibrous membrane formation occurred } \\
\text { in only two cases ( Io per cent.) although all the cases in this group had large anterior }\end{array}$} \\
\hline
\end{tabular}


chamber blood clots). The reduction of complications was also marked, although less so, in the group treated with saline, and least in the group treated conservatively. In fact, from a 20 per cent. incidence of blood clotting in the anterior chamber at the start of treatment, fibrous membrane formation occurred in 33.7 per cent. of these cases; blood clotting must have occurred while these patients were receiving conservative treatment.

The relative incidence of minor complications in the three groups is essentially similar (Table III).

Table III Incidence of minor complications

\begin{tabular}{|c|c|c|c|c|c|c|}
\hline \multirow{3}{*}{ Treatment } & \multirow{2}{*}{\multicolumn{2}{|c|}{ Conservative }} & \multicolumn{4}{|c|}{ Anterior chamber irrigation } \\
\hline & & & \multicolumn{2}{|c|}{ With saline } & \multicolumn{2}{|c|}{$\begin{array}{l}\text { With saline plus } \\
\text { Urokinase }\end{array}$} \\
\hline & No. & Per cent. & No. & Per cent. & No. & Per cent. \\
\hline Pigment on endothelium & I5 & $15 \cdot 5$ & I0 & $16 \cdot 9$ & 3 & 15 \\
\hline Pigment on lens capsule & I0 & $10 \cdot 5$ & 6 & $10 \cdot 2$ & 2 & 10 \\
\hline Pigment on vitreous & 3 & $3 \cdot 3$ & 3 & $5 \cdot 1$ & 2 & IO \\
\hline Posterior synechiae & 15 & $15 \cdot 5$ & I I & $18 \cdot 6$ & 2 & Io \\
\hline Peripheral anterior synechiae & 2 & $2 \cdot 2$ & $\mathbf{o}$ & & 0 & \\
\hline Cholesterol crystals & 3 & $3 \cdot 3$ & o & & o & \\
\hline Total cases & 98 & & 59 & & 20 & \\
\hline
\end{tabular}

\section{(3) Final visual acuity (Table IV)}

The final visual acuity is poor in all three groups, irrespective of the type of treatment. The acuity recorded is that observed on discharge. As such, it is partly related to the presence of associated ocular injuries which depend on the severity of the initiai injury rather than on the type of treatment. Their presence is often not diagnosed until the hyphaema has absorbed and their treatment is of necessity delayed.

Table IV Final visual acuity

\begin{tabular}{|c|c|c|c|c|c|c|}
\hline \multirow{3}{*}{ Treatment } & \multirow{2}{*}{\multicolumn{2}{|c|}{ Conservative }} & \multicolumn{4}{|c|}{ Anterior chamber irrigation } \\
\hline & & & \multicolumn{2}{|c|}{ With saline } & \multicolumn{2}{|c|}{$\begin{array}{l}\text { With saline plus } \\
\text { Urokinase }\end{array}$} \\
\hline & $\mathcal{N} o$. & Per cent. & No. & Per cent. & No. & Per cent. \\
\hline $6 / 18$ or better & 33 & $33 \cdot 7$ & I I & $18 \cdot 9$ & 4 & 20 \\
\hline $6 / 24$ to $6 / 60$ & I I & II $\cdot 2$ & I I & $18 \cdot 9$ & 5 & 25 \\
\hline Less than $6 / 60$ & 54 & $55^{\cdot I}$ & 37 & $62 \cdot 2$ & I I & 55 \\
\hline Total cases & 98 & & 59 & & 20 & \\
\hline
\end{tabular}

The associated ocular injuries were essentially the same in all three groups (Table V, overleaf) and this may explain the similarity in visual acuity.

There is a high incidence of vitreous haemorrhage and traumatic cataract in full hyphaemas, and it may thus be difficult to assess the underlying retina and choroid, so that the incidence of retinal oedema, retinal tears, retinal detachment, and choroidal tears is probably much higher than is shown here. These two injuries are mainly responsible 
Table V Associated ocular injuries

\begin{tabular}{|c|c|c|c|c|c|c|}
\hline \multirow{3}{*}{ Treatment } & \multirow{2}{*}{\multicolumn{2}{|c|}{ Conservative }} & \multicolumn{4}{|c|}{ Anterior chamber irrigation } \\
\hline & & & \multicolumn{2}{|c|}{ With saline } & \multicolumn{2}{|c|}{$\begin{array}{l}\text { With saline plus } \\
\text { Urokinase }\end{array}$} \\
\hline & No. & Per cent. & No. & Per cent. & No. & Per cent. \\
\hline Vitreous haemorrhage & 50 & 50 & 30 & $5^{1}$ & 9 & 45 \\
\hline Traumatic cataract & 26 & 26 & 22 & 37 & 10 & 50 \\
\hline Dislocated lens & 6 & 6 & 4 & 7 & 2 & 10 \\
\hline Traumatic iritis & 24 & 24 & 9 & 15 & 2 & 10 \\
\hline Iris sphincter tears & 6 & 6 & $\mathbf{I}$ & $1 \cdot 7$ & $\mathbf{I}$ & 5 \\
\hline Iridodialysis & 4 & 4 & o & & I & 5 \\
\hline Angle contusion & 21 & 21 & 17 & 28 & 5 & 25 \\
\hline Retinal oedema & 3 & 3 & 2 & $3 \cdot 4$ & 2 & Io \\
\hline Retinal tears & 5 & 5 & 2 & $3 \cdot 4$ & 2 & 10 \\
\hline Retinal detachment & I & I & 2 & 3.4 & 2 & 10 \\
\hline Choroidal tears & $\mathbf{I}$ & $\mathbf{I}$ & o & & o & \\
\hline No injury & 28 & 28 & 4 & $6 \cdot 7$ & $\mathbf{I}$ & 5 \\
\hline Total cases & 98 & & 59 & & 20 & \\
\hline
\end{tabular}

for the poor visual acuity. In the group treated conservatively there is a significantly higher incidence of traumatic iritis than in the other two groups.

\section{Discussion}

Early surgery is important in the management of full hyphaemas (Rakusin and Kumin 1969). Factors against continued conservative treatment include:

(I) The slow rate of absorption.

(2) The small effect on lowering the incidence of complications-in fact the results suggest that clotting had occurred while patients were actually receiving conservative treatment.

(3) The high incidence of traumatic iritis.

With traumatic hyphaemas which occupy more than three-quarters of the volume of the anterior chamber, two clinical types are recognizable, one in which the blood is mainly fluid and one in which it is clotted. In the first type blood is easily washed out with saline, but in our experience, only 45 per cent. of cases of the second type can be easily treated with saline alone. In large hyphaemas irrigation with saline succeeded in increasing the rate of absorption and decreasing the incidence of complications, but two disturbing features were noted:

(I) A high incidence ( 36 per cent.) of fibrous membrane formation. This presumably occurred as a result of organization of clots which could not be evacuated with saline.

(2) In many cases ( $3^{8}$ per cent.) the clot took longer than I week to absorb.

Obviously saline irrigation alone is often inadequate and fibrinolysis is required to dissolve the blood clot.

The ability of urine to dissolve a thrombus had long been recognized, but the active principle, Urokinase, was first isolated and purified by Ploug and Kjeldgaard (1957). This protein of human origin is entirely non-antigenic. It is a plasminogen activator and 
converts plasminogen to plasmin which digests fibrin. In the twenty cases in which Urokinase was used, it markedly increased the rate of absorption of blood from the anterior chamber and decreased the incidence of complications.

The results in patients treated conservatively and those treated with saline irrigation can be compared, but, it is not strictly accurate to include the group treated with Urokinase. These patients formed a highly selected group of the most severely traumatized eyes (in which there was a Ioo per cent. incidence of large blood clot formation in the anterior chamber and of raised intraocular pressure and a 60 per cent. incidence of corneal blood staining) in whom saline irrigation had failed. They form a group, in fact, acting as its own control, since in each patient saline was used unsuccessfully before Urokinase. They compare very favourably with the other groups, in which the trauma was less severe (as suggested by the lower incidence of glaucoma, corneal blood staining, and blood clot formation before treatment was started).

We feel that Urokinase has a significant role in the management of large traumatic hyphaema associated with large anterior chamber blood clots, and urge that it should be readily available in the operating theatre when saline irrigation is to be performed, so that it may be used immediately in difficult cases, so avoiding the need for a second surgical operation.

Our suggested schedule for the management of large traumatic hyphaemas is shown in Table VI.

Table VI Management of three-quarters to full hyphaema

(1) Conservative treatment

Should not be continued for longer than 48 hours without definite improvement (i.e. I.O.P. normal and blood absorbing).

(2) Surgery

(A) Anterior chamber irrigation with saline

Good response-when blood remains fluid -in 45 per cent. of clotted hyphaemas

(B) Anterior chamber irrigation with saline plus Urokinase

Immediately after washout with saline in cases in which blood clot remains in anterior chamber

\section{Summary}

In twenty patients who sustained traumatic hyphaemas occupying the whole of the anterior chamber together with large blood clots unsuccessful irrigation of the anterior chamber with saline was followed by the use of Urokinase. There was an increased rate of absorption and fewer complications than in two groups of similar hyphaemas treated conservatively or by irrigation with saline alone.

Early irrigation with saline should be performed in cases of traumatic hyphaemas occupying more than three-quarters of the volume of the anterior chamber, and Urokinase should be available for immediate use if saline alone is ineffective.

I wish to thank Leo Laboratories for their assistance and for supplying the Urokinase, and the Medical Superintendents of the Baragwanath and St. John Eye Hospitals for permission to publish these case records. Financial assistance for the study was provided by the University of Witwatersrand, the Medical Research Council, and the C.S.I.R. 


\section{References}

DARR, J. L., and PASSMORE, J. w. (1967) Amer. F. Ophthal., 63, I34

DUKE-ELDER, s. (1954) “Text-Book of Ophthalmology", vol. 6, pp. 5778-5784. Kimpton, London HEATH, W. (1966) Trans. ophthal. Soc. U.K., 86, 843

laughlin, R. C. (1948) Trans. Pacif. Cst oto.-ophthal. Soc., 29, 143

MACDONALD, R., JR. (1964) In "Industrial and Traumatic Ophthalmology. Symposium of the New

Orleans Academy of Ophthalmology", pp. 77-8o. Mosby, St. Louis

oksala, A. (1967) Brit. F. Ophthal., 51, 315

PIERSE, D., and LEGRICE, H. (1963) Lancet, 2, I 143

- (1964) 7. clin. Path., 17, 362

Ploug, J., and kJELdGaARD, N. o. (1957) Biochim. biophys. Acta, 24, 278

RAKUSIN, W., and KUMING, B. s. (1969) S. Afr. med. F., 43, 638

RYCHENER, R. O. (1944) F. Amer. med. Ass., 126, 763

SGHEIE, H. G., ASHLEY, B. J., and BURNs, D. T. (1963) Arch. Ophthal. (Chicago), 69, 147

ROPER-HALL, M. (1964) In "Modern Ophthalmology", ed. A. Sorsby, vol. 3, pp. 401-402. Butterworths, London

THYGESON, P., and BEARD, c. (1952) Amer. F. Ophthal., 35, 977 